\title{
Pengembangan Kantin Wirausaha Siswa SMPN 2 Porong
}

\section{Development of Students' Entrepreneurial Canteens SMPN 2 Porong}

\author{
Masruchin $^{1}$, Eni Fariyatul Fahyuni ${ }^{2}$, Bayu Hari Prasojo ${ }^{3}$ \\ Universitas Muhammadiyah Sidoarjo (Umsida), Sidoarjo, Indonesia \\ ${ }^{1}$ masruchin@umsida.ac.id, ${ }^{2}$ eni.farivatul@umsida.ac.id, ${ }^{3}$ bayu.hari@umsida.ac.id
}

Riwayat Artikel: Dikirim 26 Maret 2020; Diterima 19 November 2020; Diterbitkan 30 November 2020

\begin{abstract}
Abstrak
Pembelajaran wirausaha saat ini di sekolah masih kurang digaungkan, mengingat rasio jumlah pengusaha di Indonesia masih sangat rendah. Pengabdian bagi masyarakat yang dilakukan di SMP Negeri 2 Porong menjawab berbagai persoalan dengan memberdayakan keberadaan kantin wirausaha siswa agar nantinya siswa memiliki keterampilan berwirausaha, keberanian menghadapi tantangan, dan kemandirian berwirausaha. Metode pelaksanaan pengabdian masyarakat ini terbagai menjadi beberapa tahap, meliputi: 1) tahap perencanaan, 2) tahap pengorganisasian, 3) tahap pelaksanaan, 4) tahap monitoring dan evaluasi, 5) tahap tindak lanjut. Pengembangan dan pemberdayaan kantin wirausaha siswa di sekolah efektif menjadikan siswa lebih aktif, produktif dan bertanggung jawab dalam kehidupannya.
\end{abstract}

Kata kunci: pembelajaran kewirausahaan, kantin wirausaha siswa.

\begin{abstract}
Entrepreneurship in this time is still less echoed because the ratio of entrepreneurs in Indonesia is meager. The community of conducted at Porong 2 state middle school various problems by empowering the existence of students' entrepreneurial canteens to have entrepreneurial skills, courage to face challenges, and entrepreneurial independence. This method of implementing into several stages, including 1) the planning stage, 2) the organizing stage, 3) the implementation stage, 4) the monitoring and evaluation stage, 5) the follow-up stage. The development and empowerment of entrepreneurship canteens in schools effectively makes students more active, productive and responsible in their lives
\end{abstract}

Keywords: Entrepreneurship learning, students' entrepreneurial canteens.

\section{PENDAHULUAN}

\section{Analisis Kebutuhan}

Pendidikan memegang peran penting guna menjamin kualitas suatu bangsa. Tingkat pendidikan yang berkualitas akan menghasilkan sumber daya manusia dengan berkualitas pula. Namun pada era saat ini, siswa diharapkan tidak hanya matang dari segi intelektual, tapi juga mempunyai sifat yang terampil, kuat mental dan keberanian menerapkan keterampilan berwirausaha (Sulistyowati \& Salwa, 2016). Hal tersebut sesuai dengan UUD No 20 Tahun 2003 tentang Sistem pendidikan nasional pasal 1 ayat 1 yang menyatakan bahwa pendidikan diharapkan mampu mencapai terbentuknya aspek kognitif, aspek afektif (mental atau moral) serta psikomotor (ketrampilan).

Beberapa nilai diatas dapat
diwujudkan melalui pembelajaran
enterpreneurship (kewirausahaan) pada siswa.
Pembelajaran kewirausahaan dapat
menjadikan siswa menjadi lebih aktif,
produktif dan lebih menjadi pribadi yang
bertanggung jawab. Hasil penelitian
menunjukkan program market day
membangun jiwa kewirausahaan sehingga
berdampak pada peningkatan rasa percaya
diri, keberanian menghadapi resiko saat
barang dagangannya tidak habis terjual,
manajemen keuangan serta inovasi lainnya
yang mengarah pada jiwa kepemimpinan
siswa (Sulistyowati \& Salwa, 2016).
Membangun jiwa interprenier pada siswa
tidaklah mudah, butuh beberapa tahapan
yang panjang diantaranya: 1) tahap


perencanaan, 2) tahap pengoorganisasian, 3) tahap pelaksanaan, dan 4) tahap evaluasi (Cahyani, Timan, \& Sultoni, 2019).

Beberapa negara telah menerapkan program kewirausahaan dalam proses pembelajarannya untuk dapat mengasah keterampilan siswa. Temuan hasil penelitian menunjukkan anak usia dini (11-12 tahun) merupakan periode yang cukup untuk mengembangkan self-efficacy dan keterampilan kognitif, non-kognitif yang diperlukan untuk menjadi wirausaha di masa mendatang (Hassi, 2016). Bahkan kepala sekolah SMK 6 Palembang berkolaborasi dengan dunia industri dengan membuat kurikulum untuk melatih jiwa wirausaha siswa di sekolah (Apriana, Kristiawan, \& Wardiah, 2019).

Pembelajaran wirausaha saat ini di sekolah masih kurang digaungkan, mengingat rasio jumlah pengusaha di Indonesia masih sangat rendah. Pada tahun 2013 jumlahnya hanya mencapai 1,9\%, jumlah ini masih sangat kecil jika dibandingkan negaralainnya seperti Cina dan Jepang yang memiliki jumlah wirausaha lebih dari 10\%, serta negara tetangga seperti Malaysia (5\%) dan Singapura (7\%). Islam mengajarkan manusia bekerja dan berupaya untuk memenuhi kebutuhan akhirat tanpa melupakan pemenuhan kebutuhan lainnya di dunia. Dalam ayat-ayat al-Qur'an dijelaskan bahwasannya manusia diharuskan bekerja untuk memenuhi kebutuhanya. Hal ini sebagaimana termaktub dalam firman Allah pada surat al-Jumu'ah ayat 10 berikut ini.

Apabila telah ditunaikan sholat, maka bertebranlah kamu di muka bumi; dan carilah karunia Allah dan ingatlah Allah banyak-banyak supaya kamu beruntung (Ri, 2012).

Berdasarkan firman Allah SWT di atas dijelaskan bahwa manusia harus bekerja keras untuk memenuhi berbagai kebutuhan hidupnya selanjutnya diwajibkan melakukan kewajiban akhirat. Oleh karenanya lembaga pendidikan harus berbenah dengan mengarahkan pendidikan tidak hanya pada kompetensi intelektual saja, namun juga pada pengembangan kewirausahaan guna menyiapkan diri agar mampu memenuhi kewajiban dan kebutuhan dalam hidupnya (Darwis, 2016).

SMP Negeri 2 Porong sebelumnya telah menerapkan kantin yang dikelola oleh para siswa. Namun terdapat permasalahan mendasar yakni permasalahan dalam pengurusan aset dan administrasi keuangan. Hal ini dikarenakan siswa belum mampu mengurus asset yang dimiliki, sehingga banyak aset yang dimiliki itu tidak terurus dan rusak. Selama ini belum adanya pembinaan terkait pengelolaan keuangan. Siswa belum mampu mengatur dan menjalankan kantin sekolah secara professional. Misal terkait makanan apa saja yang dijual, sistem pengelolaan dan manajemen keuangan kantin sekolah menjadi permasalahan besar yang sampai sekarang belum bisa teratasi dengan baik.

Berdasarkan permasalahan di atas maka perlu adanya pemberdayaan kantin wirausaha siswa lebih lanjut, agar siswa memiliki pengetahuan terkait pengelolaan penjualan di kantin sekolah dan manajemen sistem keuangan kantin. Dengan dilakukannya pendampingan kantin wirausaha siswa ini nantinya diharapkan dapat menumbuhkan keyakinan diri yang positif dalam berwirausaha. Pemberdayaan kantin wirausaha siswa SMP ini agar peserta didik memiliki keberanian, kemandirian, serta ketrampilan berwirausaha di masa mendatang.

Pengembangan program kantin wirausaha siswa di SMPN 2 Porong dalam rangka mengembangkan entrepreneur muda yang berdampak positif bagi pengembangan karier dan masa depan para siswa, masyarakat dan negara. Hal ini didukung penelitian yang menjelaskan bahwa seiring dengan perkembangan zaman, hal-hal yang perlu dikuasai oleh setiap negara untuk meningkatkan keunggulannya antara lain, (1) menguasai perkembangan Iptek, 2) meningkatkan jumlah entrepreneur, (3) memiliki tenaga 
kerja yang terdidik dan terlatih dengan etos kerja tinggi, dan (4) melakukan pengendalian mutu terpadu barang yang dihasilkan, melakukan inovasi dan promosi yang aktif (Wojcak, Bajzikova, Sajgalikova, \& Polakova, 2016).

Pihak sekolah dalam hal ini sebagai institusi pedidikan memiliki peran penting dalam pengembangan kantin wirausaha siswa melalui inovasi munculnya jenis usaha-usaha baru dari hasil ide dan pemikirannya. Proses kewirausahaan meliputi semua fungsi, aktivitas dan tindakan yang berhubungan dengan peluang dan penciptaan usaha (Sulistyowati \& Salwa, 2016). Pengelolaan kantin dan managemen keuangan penting untuk disosialisasikan kepada para siswa.

Gambar 1.

Penjualan Kantin Siswa

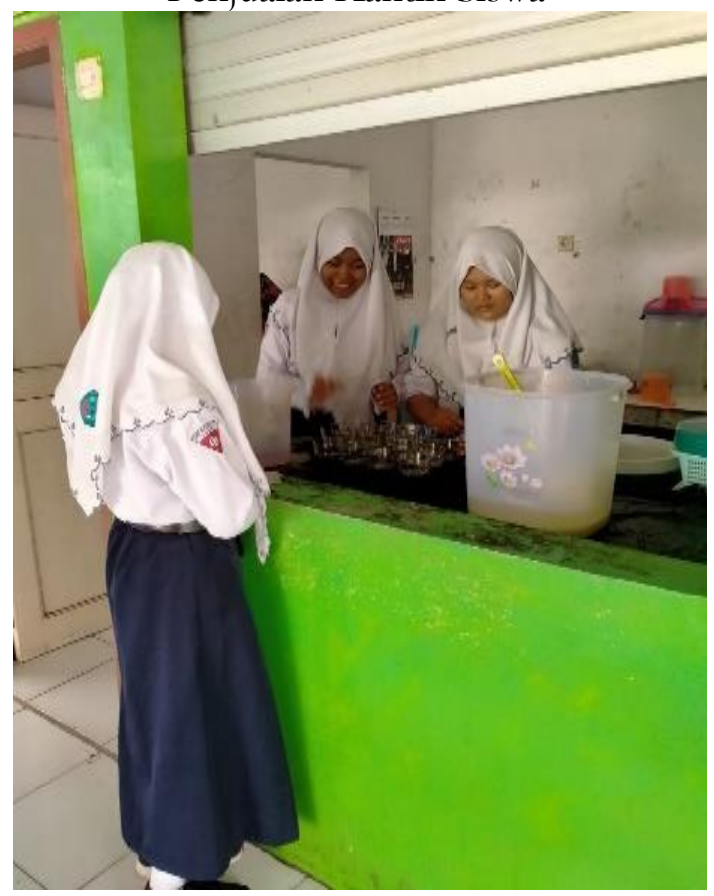

Gambar 2.

Kegiatan Wirausaha Siswa

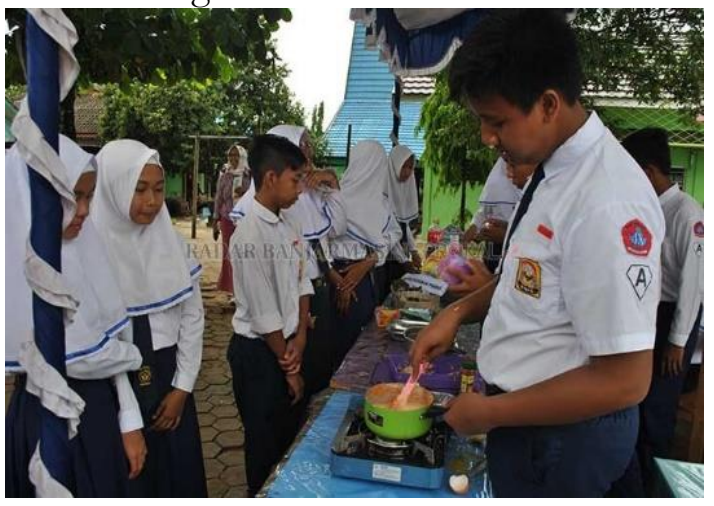

\section{Tujuan Kegiatan}

Pengembangan program kantin wirausaha siswa SMP ini bertujuan untuk:

1. Kegiatan sosialisasi untuk melatih dan mengembangkan jiwa enterpreneurship siswa

2. Mengajarkan siswa pada pengelolaan aset maupun sistem pembelian dan penjualan barang di kantin sekolah

3. Memotivasi keberanian agar memiliki kepercayaan dan keyakinan diri dalam berwirausaha

\section{METODE}

Pengabdian bagi masyarakat yang dilakukan di SMP Negeri 2 Porong yakni menjawab berbagai persoalan dengan memberdayakan keberadaan kantin wirausaha siswa agar nantinya siswa memiliki keterampilan berwirausaha, keberanian menghadapi tantangan, dan kemandirian berwirausaha. Metode pelaksanaan pengabdian masyarakat ini menjawab permasalahan dengan berbagai solusi dan Ipteks yang ditawarkan 
Gambar 3 .

Ipteks yang ditawarkan
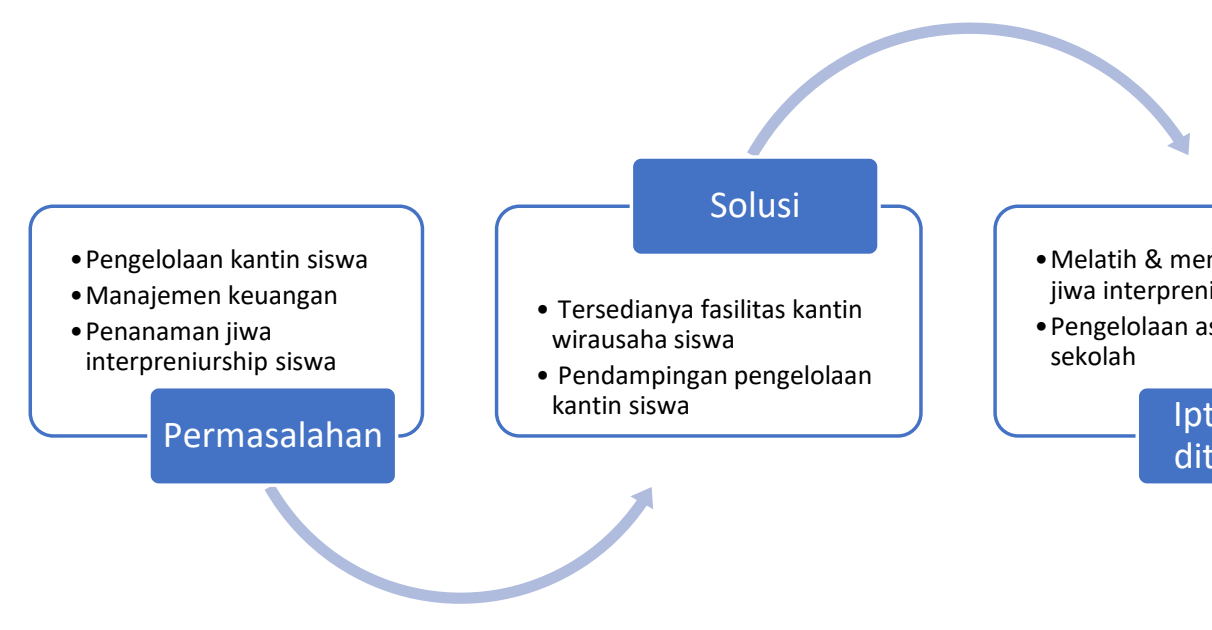

- Melatih \& mengembangkan

jiwa interpreniurship siswa

- Pengelolaan asset kantin

sekolah
Kegiatan pengabdian bagi masyarakat di sekolah ini menyangkut bidang pengetahuan, sikap dan perilaku siswa terkait kantin wirausaha bagi siswa SMPN 2 Porong untuk melatih dan membangun jiwa interpreniurship siswa melalui beberapa tahapan, diantaranya: 1) tahap perencanaan, 2) tahap pengorganisasian, 3) tahap pelaksanaan, 4) tahap monitoring dan evaluasi, dan 5) tahap tindak lanjut (Fahyuni, Rohmah, \& Anwar, 2019).

\section{Tahap Perencanaan}

Tahap perencanaan diawali menganalisis permasalahan. Hasil analisis yang diperoleh bahwa SMP Negeri 2 Porong dulunya telah menerapkan program kantin wirausaha siswa, namun terdapat permasalahan terkait pengelolaan aset dan administrasi keuangan kantin (Niati, Suhardjo, Wijayanti, \& Hanifah, 2019).

Pada tahap perencanaan ini dilakukan dengan melibatkan semua unsur sekolah yakni kepala sekolah, guru pengajar, pembina kantin sekolah, komite sekolah, dan orangtua wali siswa. Hasil diskusi yang diperoleh selanjutnya dituangkan dalam; (a) Anggaran Dasar (AD) dan Anggaran Rumah Tangga) (ART), (b) Pedoman Penyelenggaraan Pokok-Pokok Organisasi Kepengurusan Kantin, Ketiga dasar berguna menentukan arah, pengembangan dan pelaksanaan kantin wirausaha siswa SMPN 2 Porong.

\section{Tahap Pengorganisasian}

Tahap

pengorganisasian dilaksanakan dengan menyusun pihakpihak internal dan eksternal yang terlibat dalam program ini, yakni Kepala Sekolah sebagai pemangku jabatan tertinggi di sekolah, para guru dan penguurs kantin sekolah, komite sekolah, siswa dalam OSIS maupun orangtua siswa yang dapat berpartisipasi dalam penyediaan makanan yang diperjualbelikan siswa di sekolah

\section{Tahap Pelaksanaan}

Tahap pelaksanaan ini diawali kegiatan penyuluhan oleh tim pengabdian masyarakat dari Universitas Muhammadiyah Sidoarjo terkait pemberian motivasi untuk membangun keberanian dan keyakinan diri dalam berwirausaha sejak dini di sekolah. Penyuluhan dan pelatihan dilakukan di kelas maupun mushola disebabkan keterbatasan tempat dan sarana penunjang yang dimiliki sekolah. Kegiatan penyuluhan dan pelatihan ini bertujuan untuk membantu meningkatkan pemahaman terkait pengelolaan aset maupun pelaporan sistem keuangan kantin sekolah. 
Gambar 3.

Sosialisasi Wirausaha

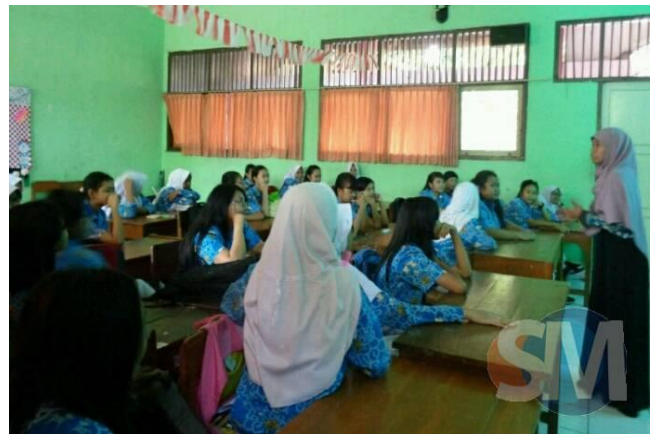

Gambar 4. Sosialisasi di Mushola

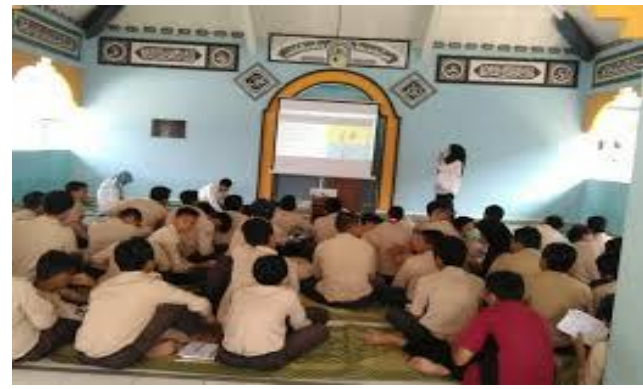

\section{Tahap Monitoring dan Evaluasi}

Tahap monitoring dan evaluasi ini melibatkan para guru dan tim pengabdian masyarakat untuk memantau kegiatan siswa pada kantin wirausaha siswa di SMPN 2 Porong. Beberapa permasalahan yang terjadi terkait dengan kantin wirausaha siswa diantaranya: a) siswa memiliki kesulitan dalam mengelola barang atau makanan dari orangtua siswa untuk dijual kembali pada kantin sekolah, b) siswa kesulitan dalam pengelolaan asset maupun system pelaporan keuangan kantin meskipun sudah pernah mendapatkan pelatihan.

Gambar 5.

Monitoring Kebersihan Kantin

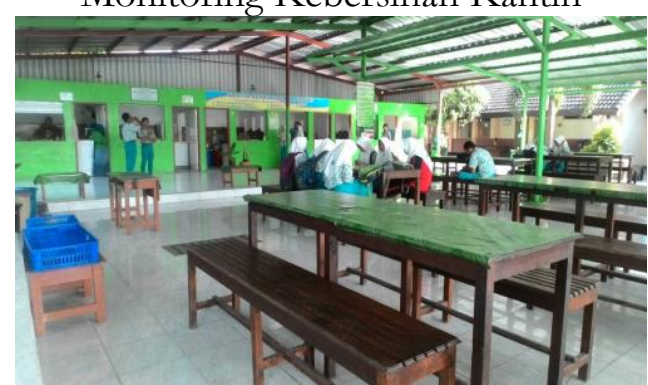

\section{Tahap Tindak Lanjut}

Tahap tindak lanjut dilaksanakan siswa pengurus kantin sekolah dibantu guru pengajar dan guru pengelola kantin untuk menemukan solusi atas persoalan yang dihadapi, diantaranya: a) menanamkan kesadaran dan tanggungjawab siswa pada kegiatan berwirausahan di sekolah agar siswa memiliki keberanian dan keyakinan diri dalam membuka dan menciptakan berbagai peluang dalam berwirausaha, b) sistem pengelolaan asset dan pelaporan keuangan dibuat semudah mungkin sehingga mudah dipahami dan dituangkan siswa dalam pelaporannya. Laba dan keuntungan kantin wirausaha siswa ini nantinya dapat digunakan untuk kepentingan peserta didik pada berbagai kegiatan studi, seperti untuk kebutuhan study tour dan classmeeting, sehingga siswa dapat merasakan dampak positifnya.

\section{HASIL DAN PEMBAHASAN}

Program Pengabdian bagi Masyarakat (IbM) ini merupakan bagian dari tugas dosen dalam melaksanakan Tri Dharma Perguruan Tinggi yang kegiatannya didanai oleh institusi UMSIDA dalam rangka mengembangkan kemajuan ilmu pengetahuan dan teknologi guna meningkatkan kesejahteraan bagi masyarakat sekolah. Pelaksanaan IbM ini meliputi beberapa tahapan diantaranya:

1. Tahap perencanaan diawali proses perijinan dan sosialisasi di SMPN 2 Porong pada tanggal 13 Desember 2019. Selanjutnya mapping permasalahan terkait pengelolaan dan pemberdayaan kantin siswa di sekolah dengan berbagai solusi yang ditawarkan dengan melibatkan semua unsur sekolah yakni kepala sekolah, guru pengajar, pembina kantin sekolah, komite sekolah, dan orangtua wali siswa.

2. Tahap pengorganisasian dengan menyusun keterlibatan pihak-pihak internal dan eksternal yakni Kepala Sekolah sebagai pemangku jabatan tertinggi di sekolah, para guru dan 
pengurus kantin sekolah, komite sekolah, siswa dalam OSIS maupun orangtua siswa yang dapat berpartisipasi dalam penyediaan makanan yang diperjualbelikan siswa di sekolah

3. Tahap pelaksanaan terkait penyuluhan selama kegiatan berlangsung yang melibatkan guru penangungjawab kantin dengan melibatkan tim Abdimas Universitas Muhammadiyah Sidoarjo untuk melakukan pendampingan meliputi sistem pengelolaan asset dan system pelaporan keuangan kantin yang dapat dipelajari dan dilaksanakan oleh siswa SMP. Pada tahap ini juga memberikan motivasi untuk membangun keberanian dan keyakinan diri siswa dalam berwirausaha dan menciptakan berbagai peluang yang ada.

4. Tahap evaluasi dan monitoring untuk mengetahui ketercapaian dari program yang telah dilaksanakan. Berdasarkan hasil kegiatan evaluasi dan monitoring inilah dapat di cek berbagai kekurangan dan faktor penghambat yang ada di lapangan.

5. Tahap tindak lanjut menjawab berbagai kendala yang terjadi dengan mencarikan solusi untuk kebaikan bersama. Tahap tindak lanjut meliputi penyempurnaan pada sistem pengelolaan aset dan pelaporan keuangan kantin siswa, serta penggunaan keuntungan kantin siswa pada berbagai kegiatan studi, seperti untuk kebutuhan study tour dan classmeeting, sehingga siswa dapat merasakan sendiri dampak positifnya.

\section{KESIMPULAN}

Kantin wirausaha siswa di sekolah dapat menghasilkan perilaku wirausaha dalam diri siswa dengan mengolah usaha untuk membekali siswa berusaha secara mandiri dan bertanggung jawab. Pendidikan kewirausahaan menanamkan nilai-nilai moral guna membentuk karakter seseorang dalam berwirausaha yang membekali siswa dengan berbagai kompetensi yang mereka butuhkan sehingga dapat memberikan pengaruh positif bagi kehidupannya.

\section{DAFTAR PUSTAKA}

Apriana, D., Kristiawan, M., \& Wardiah, D. (2019). Headmaster's competency in preparing vocational school students for entrepreneurship. International Journal of Scientific and Technology Research, 8(8), 1316-1330.

Cahyani, S. S. A., Timan, A., \& Sultoni, S. (2019). Manajemen Pelatihan Kewirausahaan Bagi Peserta Didik Di Kampoeng Kidz. Jurnal Administrasi dan Manajemen Pendidikan, 2(1), 001-009. https://doi.org/10.17977/um027v 2i22019p1

Darwis, M. (2016). Pendidikan Entrepreneurship Dalam Perspektif Global. Tarbiyatuna: Jurnal Pendidikan Islam, 9(2), 112-128.

Fahyuni, E. F., Rohmah, J., \& Anwar, N. (2019). Inovasi Pembelajaran Kewirausahaan Islami melalui Pemanfaatan Teh Rosella pada Kantin Sehat SMP. Jurnal Surya Masyarakat, $\quad 1(2), \quad 116$. https://doi.org/10.26714/jsm.1.2.2 019.116-124

Hassi, A. (2016). Effectiveness of early entrepreneurship education at the primary school level: Evidence from a field research in Morocco. Citizenship, Social and Economics Education, 15(2), 83-103. https://doi.org/10.1177/20471734 $\underline{16650448}$

Niati, A., Suhardjo, Y., Wijayanti, R., \& Hanifah, R. U. (2019). Pelatihan Pengelolaan Manajemen Keuangan dan Pelaporan Keuangan Akuntansi Pesantren bagi Pengelola Yayasan Pondok Pesantren $\mathrm{X}$ di Kota Semarang. Jurnal Surya Masyarakat, 2(1), 76. https://doi.org/10.26714/jsm.2.1.2 $\underline{019.76-79}$ 
Ri, K. A. (2012). Al Qur'an Terjemah (T. S. Qur'an, ed.). Bandung: Syaamil Qur'an.

Sulistyowati, P., \& Salwa. (2016). Upaya Mengembangkan Karakter Jiwa Kewirausahaan Pada Anak Sejak Dini Melalui Program Market Day (Kajian Pada SDIT Mutiara Hati Malang). Pancaran, Vol. 5, No(20), 111-120.

https://doi.org/https://jurnal.unej. ac.id/index.php/pancaran/article/v iew/4056/3169

Wojcak, E., Bajzikova, L., Sajgalikova, H., \& Polakova, M. (2016). How to Achieve Sustainable Efficiency with Teleworkers: Leadership Model in Telework. Procedia - Social and Behavioral Sciences, 229, 33-41. https://doi.org/10.1016/j.sbspro.2 $\underline{016.07 .111}$ 